\title{
Ancient Concepts of Nutrition and the Diet in Hunter-gatherers
}

\author{
R.B. Singh ${ }^{1, *}$, K.K. Reddy ${ }^{2}$, Jan Fedacko ${ }^{3}$, Fabien De Meester ${ }^{4}$, Agnieszka Wilczynska ${ }^{4}$ and D.W. Wilson ${ }^{5}$ \\ ${ }^{1}$ Halberg Hospital and Research Institute, Moradabad, India \\ ${ }^{2}$ Department of Anthropology, Tirupati University, Terupati, India \\ ${ }^{3}$ Faculty of Medicine, PJ Safaric University, Kosice, Slovakia \\ ${ }^{4}$ Tsim Tsoum Institute, Krakow, Poland \\ ${ }^{5}$ School of Medicine and Health, Durham University, Durham, UK
}

\begin{abstract}
Nutritional status has been implicated to be in the pathogenesis of noncommunicable diseases and long-term worldwide survival. In this relevance, the teachings of Bhagwatgita, Upanishads and Indian Vedas appear to be as old as 'Human Civilization'. The dietary formulations concomitant with relevant prescriptions provided in these scriptures appear to be as scientific as observed in cohort studies and intervention trials. These studies confirm the ancient concept reflecting that fruits, vegetables, whole grains, nuts, and milk were quite protective. In this review, the traditional concepts of nutrition to western literature have been duly introduced.
\end{abstract}

Keywords: Indian hunter-gatherers, Mediterranean diet, spiritual health, prudent diet.

\section{INTRODUCTION}

According to ancient Vedas, the span of human civilization has been divided in to four periods, namely, Satayuga, Treata, Dwaper and Kalayuga. Humans were free from diseases in Satayuga and the life expectancy was approximately 600 years. In Treata, the life expectancy reduced to 300 years, while in Dwaper to 200 years and finally in Kalayuga, it is reduced to 100 years. However, according to the modern concept, the life expectancy of the ancient man was hardly 30 years, because causes of deaths were mainly fall, bites, drowning and killing during hunting or other natural calamities but it has never been beyond 100 years. It is possible that the life expectancy appears to be dependent on physical, social, mental and spiritual health of the human beings. Decrease in physical activity, increase in mental strain, pollution, dietary changes, tobacco consumption, alcoholism and lack of humanity appear to be important contributing factors for decrease in life expectancy [1-8]. It is also known that length and brightness of the telomeres present on chromosomes are important determinants of longevity and survival. It is possible that telomeres were much larger in the ancient period indicating life expectancy more than 100 years.

In fact, the existing society can be divided into primitive hunter-gatherers, peasant-agriculturists and pastoralists, urban slum dwellers and the affluent. The majority of the human race are farmers, although there is rapid urbanization due to migration of people from rural areas, either joining the slum dwellers or becoming affluent. India and China are countries of farmers, but the rapidly growing towns have increasing numbers of poor urban slum dwellers and a sizeable affluent society. In a few states like Udissa, Jharkhand and Bihar, few primitive hunter-gatherers live their lives

*Address correspondence to this author at the Halberg Hospital and Research Institute, Civil Lines, Moradabad-10 (UP), India;

Tel/Fax: 0091591 2417437; E-mails: icn2005@bsnl.in, rbs@tsimtsoum.net outside any affluence. The world has paid only little attention towards Indian Hunter-gatherers, although Kurichia Huntergatherers appear to have highest life expectancy in India [9, 10].

It is important to focus on the diet and lifestyle of Homo sapiens and their predecessors, namely Homo erectus and Homo habilis who were primarily vegetarians. Hunting developed gradually when man moved away from the other primates and skilled in tool making, while developing social groups; hunting bands and large families [1-5]. The man started farming, about 10,000 years ago, with the technical development and upgradation of agriculture. Therefore, for about $99 \%$ of the time during which man has been evolving from primate precursors,leading towards hunter-gathering [1-7]. Apparently, our bodies have evolved well adapted for doing what hunter-gatherers do and eating what they eat and also to "when" they were eating. Thus, it has been proposed that the original skin color of man was brown, providing protection from the sun, and possibly white man evolved after settlement in Northern Europe because brown skin probably might have predisposed vitamin D deficiency causing rickets $[1,2]$. That is why, in the present review, the authors describe and introduce the ancient concepts of nutrition proposed in the Indian scriptures and diet and lifestyle of Indian hunter-gatherers for the first time to western literature in view of assessing the merits and demerits of the same to coordinate with modern concept of Nutrition.

\section{ANCIENT CONCEPTS OF NUTRITION}

The pre-historic concept of diet and nutrition is absolutely based on archeological studies, which are likely to ignore vegetable component of earlyman's diet, because remains of vegetable food in archeological sites are far less spectacular and rather more difficult to identify compared to animal bones. However, more recent archeological studies with introduction of modern technology share the same views that have already been proposed in the traditional nu- 
trition [3, 4]. In ancient scriptures of India, dietary patterns such as Sattvic, Rajasik and Tamasic have been described of which the sattvic dietary pattern appears to be similar to prudent dietary patterns (Appendix 1) [5].

Diet has also been implicated for health and disease in ancient scripture Bhagwatgita (3000 BCE). The first two lines in each of the four verses are in Sanskrit followed by its translation in English. Aayuh satvabalarogyam, sukhpreetiviverchanah, Rasyah snigdhah sthirah hradyah aharah satvikpriyah [2, 7, 8]. The sattvic foods are full of juice, good in taste and increase longevity, wisdom, power, health, happiness, peace and love Yktaharviharasya, yuktachetasya karmasu Yktaswapnavbodhasya, yogo bhavati duhkhaha $[1,6,7]$. Yoga is protective against grief to those who have disciplined diet and lifestyle and controlled bahaviour; sleep and awakening. Katvamlalavanatyusnteekshanaruksha vidahinah Ahar rjassyestah, dukhahshokmaypradah [1, 7, 9]. The foods that are bitter, acid, fried, hot, pungent and dry Give rise to grief, mental stress and diseases. Yatyaman gatarasam, pootiparyushitachya yat, Uchhistamapi chamedhyam, bhojanam tamspriyam $[1,7,10]$. Foods that are cold, prickled, putred and preserved are lured to Criminals and give rise to criminal tendency and behaviour.

Adverse effects of diet and lifestyle were also known to our great physician Charaka and Sushruta (600 BCE). Charaka (600BCE), proposed that, "Heart attack is born by the intake of fatty meals, overeating, excess of sleep, lack of exercise and anxiety". Charaka Sutra, 600BC. Charaka supposedly lived in Taxila University in the north of India and was a Brahman physician. However, Sushruta was a surgeon from the Vishwamitra family of Varanasi in east of India. In Mahabharata, he is represented as a son of that royal sage. The Garuda Puranam places Divodasa as $4^{\text {th }}$ in descent from Dhanavantari, the first propounder of the medical sciences upon earth, whereas the Sushruta samhita describes both as same persons. Sushruta being a surgeon, gave a more clear description of atherosclerosis or madroga; "Excess intake of fatty foods and lack of exercise causes obesity and narrowing of the channels taking blood to the heart. It is useful to use guggul, triphala and shilajit treatment. Since the days of ancient Greece, doctors in all countries used to provide dietary advice to their patients in the treatment". These herbs are known to have a high content of antioxidant flavonoids, vitamins and minerals as well as fibers. Hippocrates used to frequently give dietary advice to the patients during treatment.

In the $7^{\text {th }}$ century $\mathrm{BC}$, a Chinese physician proposed that "increased consumption of salt may cause hardening of the pulse". About 2500 years ago from now(512 BCE), Confucius, the Chinese philosopher taught his students, "the higher the quality of foods, the better and never rely upon the delicacy of cooking". Thus a dietary guideline based on experience, observation and thinking was given as; "cereals, the basic, fruits the subsidiary, meat the beneficial and vegetable the supplementary". Therefore, according to WHO experts 1990, the concept of eating a diet high in animal foods, and preference for meat and greasy foods was well shaped in China. However, possibly the meat was considered to be rich in w-3 fatty acids, and the total fat intake remained within desirable limits and was not excessive as in the Western countries. After development of agriculture, about 10,000 years ago, food was easily available and stored but the major changes in the human diet had occurred in the last 150 years. There is an opportunity to get aware about the food intakes of man before development of farming, by studying the diets of hunter-gatherers [1-3].

\section{THE INDIAN HUNTERGATHERERS}

The Kurichias of Wayanad plateau, inhabit at the trijunction of Kerala, Karnataka and Tamilnadu in South India $[9,10]$. They live in enormous joint families and follow a commune type of family organization. The elderly Kurichia constitute about $12 \%$ in their general population which is two-fold greater compared to elderly subjects $(6.5 \%)$ among other Indian populations. The proportion of elderly Kurichias is almost closer to that of many developed countries (10$14 \%)$. Kurichias live in scattered home-steads on leveled grounds adjacent to their agricultural fields, and the distance between one such settlements to another probably ranging from 2 to $10 \mathrm{~km}$. Their massive joint families maintain a matrilineal heritage that can be well understood in several aspects such as leadership and its succession, property inheritance, management of the family on an egalitarian basis. The rural and land owning Kurichias strictly adhere to their culture following matriline age. The older generation also continues to have the leadership control over the family. The senior most of the family member is given due importance in all walks of life, even after retiring from head-manship, The excellent ecology is another factor for the longevity of the Kurichias inhabiting Wayanad region of Kerala receives maximum rainfall in the State of Kerala.

Kurichias possess strong physique although they have recently started farming in which all the members of the family participate in cultivation. They are fond of hunting and the work environment of Kurichias is located in the midst of two hills. Kurichias daily walk for 10-20 miles every day which is characteristic of hunting and farming as hunter-gatherers. Obesity and overweight are not seen among them $[9,10]$. Ownership of land is collective among the Kurichias, which facilitates them to lead a inexpensive life. They are not interested in the accumulation of wealth but now they have started storing food for next few months. Elderly people exhibit anxiety over the ambitious attitude of younger generation who want to accumulate wealth. Causes of deaths among Kurichias are mainly fall, bites, drowning and killing during hunting or other natural calamities. Cancer, heart attack, hypertension, obesity and diabetes mellitus are uncommon among Kurichia hunter-gatherers [9, 10].

\section{FOOD INTAKES AMONG INDIAN HUNTER- GATHERERS}

The food consumption pattern of the Indian huntergatherers has some similarity with the food consumed by other hunter-gatherers [1-3]; vegetables, leaves, nuts, tubers, fruits, whole grains, eggs, fish, honey. Indian Kurichia hunter-gatherers are known to be non-vegetarians. Meat is taken mostly from the untamed animals and the time of hunting was possibly, early in the morning, at sun rise when animals come for drinking of water at the river banks. They are fond of taking fresh meat that is hunted by themselves for consumption. Since the government of India has imposed ban on hunting in the forest, their meat intake is now drastically reduced as given in the appendix 2 and tables. Dietary 
intakes assessed by 3-days dietary recall, were recorded in a questionnaire, by the dietitian and by asking food intake frequency in the last one month. Food models, food measures and food portions were showed to individuals with the help of an educated Kurichia, who knew both the languages, during dietary assessments.

The dishes taken by Kurichias will predominantly occupy with green leaves like Cassia tora, Alternanthera sessilis etc, vegetable like hydrocotyle, clerodendron, nymphaea nouchali and roots like ceropegia and elaeocarpus $[9,10]$. In fact, sugar is a recent addition during the last 50 years. The main foods are; brown rice, seasonal green leaves and fruits, roots and tubers, fish, and butter milk. Alcohol and tobacco intakes are considered evils which are uncommon. These foods are rich sources of w-3 fatty acids, antioxidants, essential amino acids, vitamins and minerals and soluble fiber and are low in saturated fat, w-6 fat and trans fat. Sugar is the only refined carbohydrate. The food and nutrient intakes among Kurichias appear to have similarity with the food advised in the ancient scriptures classically known as Rajasik diet (Appendix I).

\section{ARCHIOLOGICAL CONCEPTS OF NUTRITION}

A fundamental view of evolution in relation to health promotion has been that the genetic makeup of contemporary humans shows minor difference from that of the modern humans who appeared in Africa between 100,000 and 50,000 years ago $[4,5]$. The human evolution has been comparatively rapid during the past 50,000 years, as revealed by the molecular geneticists. There have been marked changes in the food supply with the development of agriculture about 10,000 years ago from now. However, only non-significant change in our genes occurred, during the past 10 century, due to presence of w-3 fatty acids, essential amino acids, antioxidants, vitamins and minerals in the diet. The spontaneous mutation rate for nuclear DNA is estimated at $0.5 \%$ per million years. Hence, over the past 10,000 years there has been time for very little change in our genes, possibly $0.005 \%$. Our genes appear to be similar to the genes of our ancestors during the Paleolithic period 40,000 years ago, the time when our genetic profile was established. Man appears to live in a nutritional environment which completely differs from that for which our genetic constitution was selected. However, during the last 100-160 years, dietary intakes have changed significantly, causing increased intake of saturated fatty acids (SFA), trans fatty acids and linoleic acid and decrease in w-3 fatty acids, from grain fed cattle, tamed at farm houses, rather than meat from running animals. In general, there is increase in the intake of refined carbohydrates and decrease in the intake of complex carbohydrates, essential amino acids, minerals, vitamins and antioxidants. The food and nutrient intake among hunter-gatherers and during $\mathrm{Pa}$ leolithic period are given in the Tables 1-5. There is marked reduction in consumption of $\mathrm{w}-3$ fatty acids, antioxidants, vitamins and minerals and proteins and significant increase in the intakes of carbohydrates, ( mainly refined,), fat (saturated, trans fat, linoleic acid) and salt compared to Paleolithic period [4-10]. These dietary changes in conjunction with sedentary behavior, mental strain, pollution, tobacco consumption and alcoholism, particularly after 1910, during the last 100 years may have caused damage to our genes, leading to emergence of non-communicable diseases. The protective effects of Paleolithic diets in the form of Mediterranean diet, Indo-Mediterranean diet, Japanese diet, and DASH diet have been documented in the several previous studies [11-20]. The traditional concepts of nutrition, particularly, Rajasic diet and the foods consumed by Indian hunter-gatherers also support the consumption of natural foods, similar to these diets. These studies have clearly demonstrated the beneficial impacts of these diets, against coronary artery disease, hypertension, type 2 diabetes mellitus and cancers [10-20].

The Columbus concept of diet means that humans evolved on a diet that was low in saturated fat and the amount of w-3 and w-6 fatty acids was quite equal $[7,8]$. Nature recommends to ingest fatty acids in a balanced ratio (polyunsaturated:saturated $=\mathrm{w}-6: \mathrm{w}-3=1: 1$ ) as part of dietary lipid pattern in which monounsaturated fatty acids $(\mathrm{M})$ is the major fat(P:M:S=1:6:1). These ratios represent the overall distribution of fats in a natural untamed environment. (www.columbus-concept.com). The Columbus foods include egg, milk, meat, oil, whole grain foods, all rich in w-3 fatty acids, similar to wild foods, consumed about 160 years ago

Table 1. Food and Nutrient Intake Among Hunter-Gatherer and Western Population

\begin{tabular}{|l|l|l|l|}
\hline Food and Nutrient & Hunter-Gatherer & Western Population & Asians \\
\hline \hline Energy density & Low & High & Low \\
Protein & High & Low-moderate & Low \\
Animal & High & Low -moderate & Low \\
Vegetable & Very low & Low-moderate & Low \\
Carbohydrate & Low-moderate(slowly absorbed) & Moderate-rapidly absorbed & High-Slow \\
Fiber & High (>30g) & & High \\
Fat & Low & Low (<15g) & Low \\
Animal & Low & High & Low \\
Vegetable & Very low & High & High \\
Total w-3 & High(2.3g/day) & Low (0.2g/day) & High 15-20 \\
Ratio w-6:w-3 & Low 2.4 & low & $25-50$ \\
Vitamins and minerals & high & High \\
\hline
\end{tabular}

Modified from Eaton et al. 1998 and Singh et al. 2011, ref [4, 6]. 
Table 2. Estimated Fatty Acid Consumption in the Late Paleolithic Period

\begin{tabular}{|c|c|}
\hline Sources & Fatty Acids(g/day) en 35.65/day \\
\hline \multicolumn{2}{|l|}{ Plants } \\
\hline Linoleic acid & 4.28 \\
\hline Alpha-linoleic acid & 11.40 \\
\hline \multicolumn{2}{|l|}{ Animal } \\
\hline Linoleic acids & 4.56 \\
\hline Alpha-linolenic acid & 1.21 \\
\hline \multicolumn{2}{|l|}{ Total } \\
\hline Linoleic acid & 8.84 \\
\hline Alpha linolenic acid & 12.60 \\
\hline \multicolumn{2}{|l|}{ Animal } \\
\hline Arachidonic acid(w-6) (AA) & 1.81 \\
\hline \multicolumn{2}{|l|}{ Long chain $w-3$ fatty acids } \\
\hline Eicosapentaenoic acid(w-3)(EPA) & 0.39 \\
\hline Docosatetraenoic acid(w-6) (DTA) & 0.12 \\
\hline Docosapentaenoic acid(w-3)(DPA) & 0.42 \\
\hline Docosahexaenoic acid(w-3)(DHA) & 0.27 \\
\hline Total long chain w-3 fatty acids & 1.20 \\
\hline Ratios of w-6/w-3 & 0.70 \\
\hline Linoleic acid/alpha linolenic acid+ & 1.79 \\
\hline $\mathrm{AA}+\mathrm{DTA} / \mathrm{EPA}+\mathrm{DPA}+\mathrm{DHA}$ & \\
\hline Total w-6/w-3 & 0.77 \\
\hline
\end{tabular}

Modified from Eaton et al. ref 4 and Singh et al. 2011, Ref [6].

Table 3. Nutrient Composition in the Late Paleolithic and Current Recommendations

\begin{tabular}{|l|l|l|}
\hline Nutrient Per Day & Late Paleolithic & Current Recommendation \\
\hline \hline Total dietary energy\% & & \\
Protein & 33 & 12 \\
Carbohydrate & 46 & 58 \\
Fat & 21 & 30 \\
Alcohol & -0 & moderate alcohol \\
P/S ratio & 1.41 & 1.00 \\
Cholesterol, mg & 520 & 300 \\
Fiber,g & $100-150$ & $30-60$ \\
Sodium, mg & 690 & $1100-3300$ \\
Calcium, mg & $1500-2000$ & $800-1600$ \\
Ascorbic acid, mg & 440 & 60 \\
\hline
\end{tabular}

Modified from Eaton et al. ref 4 and Singh et al. 2011, Ref [6].

Table 4. Ethnic Differences in Fatty Acid Levels in Thrombocytes Phospholipids and Percentage of All Deaths from Cardiovascular Disease

\begin{tabular}{|l|l|l|l|}
\hline & Europe and USA \% & Japan \% \\
\hline \hline Arachidonic acid(20:4w6) & 26 & 21 & 8.3 \\
Eicosapentaenoic acid(20:5w-3) & 0.5 & 1.6 & 8.0 \\
Ratio of w-6/w-3 & 50 & 12 & 1 \\
Mortality from cardiovascular disease & 45 & 12 & 7 \\
\hline
\end{tabular}

Modified from Singh et al. JAMR 2011, Ref [6]. 
Table 5. Fatty Acids Ratio in the Diets

\begin{tabular}{|l|l|l|}
\hline Subjects & $\mathbf{w - 6 / w - 3}$ & \\
\hline \hline Paleolithic & 0.79 & Estimated \\
Greece prior to 1960 & $1.00-2.00$ & Current 7.10 \\
Japan & 4.00 & Early 1-2 \\
India, rural & $5-6.1$ & Prior to $1960,3-4$ \\
India urban & $38-50$ & Prior to 1960, 5-10 \\
UK & 15.00 & Prior to 1960,10.00 \\
Northern Europe & 15.00 & Prior to 1960,10.00 \\
USA & 16.74 & Prior to 1950 7-8 \\
Eastern Europe & $20-25$ & Estimated \\
Indian hunter-gatherers & $1.00-2.00$ & Estimated \\
\hline
\end{tabular}

Modified from Singh et al. 2011, ref 6.

from now. Blood lipid composition does reflect one's health status: (a) circulating serum lipoproteins and their ratio provide information on their atherogenicity to blood vessels and (b) circulating plasma fatty acids, such as w-6/w-3 fatty acid ratio, give indication on proinflammatory status of blood vessels.; (a) and (b) are phenotype-related and depend on genetic, environmental and developmental factors. As such, they appear as universal markers for physical, mental, social and spiritual health that are more clearly described in the Tsim Tsoum concept (http://www.tsimtsoum.net/editorials/ tsimtsoum_editorial_2009-Kosice-14th-WCCN-and-5th-ICCD. pdf). Blood cholesterol may be central to this approach, however, it also includes simultaneous approach for protecting mind-body interactions against environmental factors.
The word Tsim Tsoum is derived from Hebreu and it is similar to ying yang in Chinese and is the indicator of total health.

Conclusively, the acient concepts of nutrition appear to be sound for providing an advice on eating natural foods; fruits, vegetables, roots and tubers, sprouted whole grains, nuts, cow milk and curd and honey and on the adverse effects of fried and preserved foods. There is no advice for animal foods; eggs, fish and meat from running animals commonly consumed by hunter-gatherers, which may be an ignorance or a wisdom for spiritual health. However, Rajasic diet advised for fighters is similar to this diet (Appendix I).

\section{APPENDIX 1}

Dietary advice in ancient Ayurveda.(Maha-anaarany Upanishad, 5000 BCE)

1. Sattvic diet. Advised to saints. Contains fruits, vegetables, sprouted grains, roots, tubers, nuts, cow milk, curd, and honey.

It would enhance, longevity, health, happiness and spirituality and possible survival may be 100-150 years. Good for mental, social and spiritual health.

2. Rajasic diet. Advised to kings and fighters. Contains fruits, vegetables, nuts, meats from hunted animals, clarified butter, butter, curd, honey, spices, wines.

It may cause excitement, confidence and increase intelligence with life expectancy of about 100 years. Good for physical, mental and social health.

3. Tamasic diet. Not advised. Contains high fat fried foods, rich in salt, sugar, spices, chillies, meats from big tamed animals, butter and liquor.

This diet makes one dull, enhances anger and criminal tendency and impedes spiritual progress.

Life expectancy was much lower. Bad for health. 


\section{APPENDIX II}

Food consumption pattern among Indian hunter-gatherers

Morning: Most take milk or nothing but few prefer to have black tea (Fresh tea leaves that is available in their paddy fields will be taken, boiled in the water and then take with sugar)

Breakfast: Majority of the people (around 95\%) prefer to have Gangi in the morning for about $200 \mathrm{~g}$ to $300 \mathrm{~g}$. (Gangi: Brown rice mixed with Ragi and then kept over night in the water for fermentation and then take the semi solid mixed with water). This will be supplemented with some self made pickle.

Lunch: They prefer to have brown rice only (cultivated from their fields without use of fertilizers). Rice cooked (200-300g) will be supplemented with green leaves (100-200g, seasonally available) and a fried fish, 100-200g (fresh water) available in their canals. They take some quantity of seasonal fruits, $100-200 \mathrm{~g}$ daily.

Evening: Few people prefer to have black tea (Fresh tea leaves that is available in their paddy fields will be taken, boiled in the water and then take with sugar)

Night: They prefer to have brown rice only (yielded from their fields only). Rice will be supplemented with seasonal green leaves (100-200g/day) and a fried fish(150-300day) available in their canals and buttermilk (100-300ml). They take some quantity of fruit (100-200g).

\section{REFERENCES}

[1] Loomis WF. Skin pigment regulation of vitamin D biosynthesis in man. Science 1967; 157: 501-6.

[2] Lee RB. What hunters do for a living: A comparative study. In: Lee RB, Devore I, Eds. Man the Hunter, Aldine: Chicago 1968; 41-3.

[3] Singh RB, De Meester F, Wilczynska A. The Tsim Tsoum approaches for prevention of cardiovascular diseases. Cardiology Research and PracticeVolume, 2010, ArticleID, 824938, 18pages, doi:10.4061/2010/824938

[4] Eaton SB, Eaton SB III, Sinclair AJ, Cordain I, Mann NJ. Dietary intake of long chain polyunsaturated fatty acids during the Paleilithic period. In: Simopoulos AP Ed. The return of w-3 fatty acids in the food supply. Land based Animal Food Products and their Health Effects. World Rev Nutr Dietetics 1998; 83: 12-23.

[5] Eaton B. Evolution and cholesterol. World Rev Nutr Diet 2009; 100: 46-54.

[6] Singh RB, Moshiri M, De Meester F, Juneja L, Muthusamy V, Manoharan S. The evolution of low w-6/w-3 ratio dietary pattern and risk of cardiovascular diseases and diabetes. J Altern Med Res 2011; 3(in press)

[7] De Meester F. Wild-type land based foods in health promotion and disease prevention: the LDL-CC:HDL-CC model. In: Wild Type Foods in Health Promotion and Disease Prevention, Ed. Fabien De Meester, RR Watson, Humana Press, NJ 2008, 3-20.

[8] De Meester F. Progress in lipid nutrition: the Columbus concept addressing chronic diseases. World Rev Nutr Diet 2009; 100: 11021.

[9] Reddy KK, Papa Rao A, Reddy TPK. Serum Vitamins E, A and lipid peroxidation levels in Kurichias, an Indian tribal population. Ind J Biochem Biophys 1999; 36: 44-50.

[10] Reddy KK, Reddy TPK, Reddy BK, PapaRao A, Singh RB. A sociocultural perspective of centerians in a tribal community of south India. Help Age India Res Dev J 2006; 12: 30-36.
[11] Fung TT, Chiuve SE, McCullough ML, Rexrode KM, Logroscino G, Hu FB. Adherance to DASH- style diet and risk of coronary heart disease and stroke in women. Arch Intern Med 2008; 168: 713-20.

[12] Sack FM, Svetkey LP, Vollmer WM, et al. Effects on blood pressure of reduced dietary sodium and the Dietary Approaches to Stop Hypertension (DASH) diet. N Engl J Med 2001; 344: 3-10.

[13] Obarzanek E, Sacks FM, Vollmer WM, et al. Effects on blood lipids of a blood pressure-lowering diet: the Dietary Approaches to Stop Hypertension (DASH) Trial. Am J Clin Nutr 2001; 74: 80-89.

[14] Katcher HI, Legro RS, Kunselman AR, et al. The effects of whole grain- enriched hypocaloric diet on cardiovascular disease risk factors in men and women with metabolic syndrome. Am J Clin Nutr 2008; 87: 79-90.

[15] Singh RB, Beegom R, Verma SP, et al. Association of dietary factors and other coronary risk factors with social class in women in five Indian cities. Asia Pac J Clin Nutr 2000; 9: 298-302.

[16] Aratti P, Peluso G, Nicolai R, Calvani M. Polyunsaturated fatty acids:biochemical, nutritional and epigenetic properties. J Am Coll Nutr 2004; 23: 281-302.

[17] Simopoulos AP. Is Insulin Resistance Influenced by Dietary Linoleic Acid and Trans Fatty Acids?. Free Radic Biol Med 1994; 17: 367-72.

[18] Singh RB, Dubnov G, Niaz MA, et al. Effect of an IndoMediterranean diet on progression of coronary disease in high risk patients: a randomized single blind trial. Lancet 2002; 360: 145561.

[19] Trichopoulou A, Bamia C, Trichopoulos D. Anatomy of health effects of Mediterranean diets. Greek epic prospective heart study. BMJ 2009; 338: b2337.

[20] De Lorgeril M, Renaud S, Mamelle N, et al. Mediterranean alphalinolenic acid-rich diet in secondary prevention of coronary heart disease. Lancet 1994; 343(8911): 1454-9. 